This is the final peer-reviewed accepted manuscript of:

Mitochondrial F1Fo-ATPase and permeability transition pore response to sulfide in the midgut gland of Mytilus galloprovincialis.

Algieri C, Nesci S, Trombetti F, Fabbri M, Ventrella V, Pagliarani A. Biochimie. 2020; 180: 222-228.

The final published version is available online at: https://doi.org/10.1016/j.biochi.2020.11.012

Rights / License:

The terms and conditions for the reuse of this version of the manuscript are specified in the publishing policy. For all terms of use and more information see the publisher's website.

This item was downloaded from IRIS Università di Bologna (https://cris.unibo.it/)

When citing, please refer to the published version. 
This is the final peer-reviewed accepted manuscript of:

Mitochondrial $\mathrm{F}_{1} \mathrm{~F}_{\mathrm{O}}$-ATPase and permeability transition pore response to sulfide in the midgut gland of Mytilus galloprovincialis.

Algieri C, Nesci S, Trombetti F, Fabbri M, Ventrella V, Pagliarani A. Biochimie. 2020; 180: 222-228.

The final published version is available online at: https://doiorg.ezproxy.unibo.it/10.1016/j.biochi.2020.11.012

Rights / License:

The terms and conditions for the reuse of this version of the manuscript are specified in the publishing policy. For all terms of use and more information see the publisher's website. 


\section{Mitochondrial $\mathrm{F}_{1}$ Fo-ATPase and permeability transition pore response to sulfide in the midgut gland of Mytilus galloprovincialis}

Cristina Algieri, Salvatore Nesci*, Fabiana Trombetti, Micaela Fabbri, Vittoria Ventrella, Alessandra Pagliarani

Department of Veterinary Medical Sciences (DIMEVET), University of Bologna, via Tolara di Sopra, 50, 40064 Ozzano Emilia (Bologna), Italy

*Corresponding author: salvatore.nesci@unibo.it

Declaration of interest

None.

Abbreviations: CRC, calcium retention capacity; EDTA, ethylenediammine tetraacetic acid; DMSO, Dimethylsulphoxide; HEPES, (4-(2-hydroxyethyl)-1-piperazinethanesulfonic acid); mPTP, mitochondrial permeability transition pore; Tris, Tris(hydroxymethyl)-aminomethane. 


\begin{abstract}
The molecular mechanisms which rule the formation and opening of the mitochondrial permeability transition pore (mPTP), the lethal mechanism which permeabilizes mitochondria to water and solutes and drives the cell to death, are still unclear and particularly little investigated in invertebrates. Since $\mathrm{Ca}^{2+}$ increase in mitochondria is accompanied by mPTP opening and the participation of the mitochondrial $\mathrm{F}_{1} \mathrm{~F}_{\mathrm{O}}$-ATPase in the $\mathrm{mPTP}$ is increasingly sustained, the substitution of the natural cofactor $\mathrm{Mg}^{2+}$ by $\mathrm{Ca}^{2+}$ in the $\mathrm{F}_{1} \mathrm{~F}_{\mathrm{O}}$-ATPase activation has been involved in the mPTP mechanism. In mussel midgut gland mitochondria the similar kinetic properties of the $\mathrm{Mg}^{2+}-$ or $\mathrm{Ca}^{2+}$-dependent $\mathrm{F}_{1} \mathrm{~F}_{\mathrm{O}}$-ATPase activities, namely the same affinity for ATP and bi-site activation kinetics by the ATP substrate, in spite of the higher enzyme activity and coupling efficiency of the $\mathrm{Mg}^{2+}$-dependent $\mathrm{F}_{1} \mathrm{~F}_{\mathrm{O}^{-}}$ ATPase, suggest that both enzyme activities are involved in the bioenergetic machinery. Other than being a mitochondrial poison and environmental contaminant, sulfide at low concentrations acts as gaseous mediator and can induce post-translational modifications of proteins. The sulfide donor NaHS, at micromolar concentrations, does not alter the two $\mathrm{F}_{1} \mathrm{~F}_{\mathrm{O}}-\mathrm{ATPase}$ activities, but desensitizes the mPTP to $\mathrm{Ca}^{2+}$ input. Unexpectedly, NaHS, under the conditions tested, points out a chemical refractoriness of both $\mathrm{F}_{1} \mathrm{~F}_{\mathrm{O}}$-ATPase activities and a failed relationship between the $\mathrm{Ca}^{2+}$-dependent $\mathrm{F}_{1} \mathrm{~F}_{\mathrm{O}}$-ATPase and the mPTP in mussels. The findings suggest that mPTP role and regulation may be different in different taxa and that the $\mathrm{F}_{1} \mathrm{~F}_{\mathrm{O}}$-ATPase insensitivity to NaHS may allow mussels to cope with environmental sulfide.
\end{abstract}

\title{
Keywords
}

$\mathrm{F}_{1} \mathrm{~F}_{\mathrm{O}}$-ATPase; mitochondria; midgut gland, Mytilus galloprovincialis; permeability transition pore; sulfide. 


\section{Introduction}

Sulfide is an important environmental agent for a variety of aquatic and terrestrial organisms. In recent years studies on sulfide effects have been mainly focused on mammals, due to the emerging sulfide role as physiological gaseous modulator and its involvement in cardiovascular [1] and liver [2] protection. Marine habitats have received most attention for the occurrence of hydrothermal vents and hypoxic habitats, where high sulfide concentrations impose biological adaptations to allow survival [3]. However, sulfide is a naturally produced compound which affects and drives biochemical events from bacteria to mammals, and, depending on the dose and the available targets, may be a respiratory and neurological poison, a signaling molecule [4], and also have therapeutic potential [1]. In aquatic biota sulfide toxicology has common features, especially at the biochemical level, which affect health, survival, productivity and distribution of aquatic species [5].

In aqueous solutions, $\mathrm{H}_{2} \mathrm{~S}$ reversibly dissociates into the hydrosulfide ( $\left.\mathrm{HS}^{-}\right)$and bisulfide ( $\mathrm{S}^{2-}$ ) anions, whose proportion is $\mathrm{pH}$ and temperature dependent. At physiological $\mathrm{pH}(7.4)$ and temperature (37 ${ }^{\circ} \mathrm{C}$ ), the most abundant forms are $\mathrm{HS}^{-}$(nearly $70 \%$ ) and $\mathrm{H}_{2} \mathrm{~S}$ (about 30\%). The latter is moderately lipophilic and can cross biological membranes. At increasing pHs, as in seawater, the $\mathrm{H}_{2} \mathrm{~S}$ level decreases, while $\mathrm{HS}^{-}$and $\mathrm{S}^{2-}$ concentrations increase and may somehow contribute to sulfide bioactivity, even if the negative charges most likely prevent membrane crossing. However, the quantification of the actual concentration of these three species is not easy and often controversial [6,7], so the term sulfide is currently used to embrace the three interconverting forms [8].

Mitochondria provide the main defense against environmental sulfide [5] and also constitute one of its preferred targets [9]. Sulfide can affect mitochondrial proteins by directly producing post translational modifications of aminoacid residues such as cysteine, and/or by indirectly affecting redox homeostasis [10]. Controversial effects were reported on the pro-oxidant and anti-oxidant effects of $\mathrm{H}_{2} \mathrm{~S}$ and on its modulation of mitochondrial bioenergetics [11].

As far as we are aware no study has dealt with a direct effect of sulfide on the mitochondrial $\mathrm{F}_{1} \mathrm{FO}_{\mathrm{O}}$ ATPase, which plays a central role in the production of ATP under aerobic conditions and, as recently emerged, in the cell lifespan [12]. The mitochondrial $\mathrm{F}_{1} \mathrm{~F}_{\mathrm{O}}$-ATPase has been increasingly involved in the formation of the permeability transition pore (mPTP), which dramatically increases the inner mitochondrial membrane permeability and drives the cell to death. This lethal task, triggered by an increase in $\mathrm{Ca}^{2+}$ concentration in the mitochondrial matrix which activates the hydrolytic activity of the $\mathrm{F}_{1} \mathrm{~F}_{\mathrm{O}}$-ATPase [13,14], is established in mammals $[15,16]$, but still uncertain in invertebrates where it could depend on the so called lipidome, namely the lipid composition of the inner mitochondrial membrane [17,18], which may affect the membrane flexibility required to form the pore. 
Accordingly, the formation of the mPTP was only described in sea urchin gametes [19], hypothesized in the opistobranch mollusk Aplysia [20] and undetected in crustaceans [21]. Clues of pore forming properties of $\mathrm{F}_{1} \mathrm{~F}_{\mathrm{O}}$-ATPase dimers were found in model organisms, namely Drosophila and yeast [22]. To our knowledge, there are no reports in bivalve mollusks, whose mitochondrial $F_{1} F_{0}-A T P a s e$ mechanism exhibits some astonishing similarities to mammals [23]. Sulfide accumulates below mussel farms [24] and has a great impact on benthic populations [5].

The present work aims at casting light in a quite unexplored field, by testing sulfide effects on the mitochondrial $\mathrm{F}_{1} \mathrm{~F}_{\mathrm{O}}$-ATPase activated either by the natural cofactor $\mathrm{Mg}^{2+}$ or by $\mathrm{Ca}^{2+}$ in the midgut gland of Mytilus galloprovincialis, a widely cultivated species in the Mediterranean Sea. Interestingly, bivalve mollusks constitute emerging animal models to study molecular mechanisms, such as those involved in cancer [25], muscle contraction [26], inflammation [27] and aging [28], other than having a recognized role in ecotoxicology [29]. The results may also contribute to improve the knowledge of sulfide physio-pathological roles and of the mitochondrial responsiveness to sulfide in invertebrates under aerobic conditions.

\section{Materials and Methods}

\subsection{Chemicals}

NaHS, oligomycin (a mixture of oligomycins A, B and C) and Fura-FF were purchased from VinciBiochem (Vinci, Italy). Na $\mathrm{NaTP}_{2}$ was obtained from Sigma-Aldrich (Milan, Italy). Quartz double distilled water was used for all reagent solutions.

\subsection{Animals}

Adult specimen of commercial size (mean average weight $20 \mathrm{~g},>25 \mathrm{~mm}$ shell length) of mussels Mytilus galloprovincialis Lamark were obtained from coastal culture plants in the Northern Adriatic Sea and transported alive in aerated seawater tanks to the laboratory. Approximately 60 mussels were used, divided into pools of 10-15 animals each. According to the Italian law, the use of commercially available bivalve shellfish for research purpose does not require any approval.

\subsection{Preparation of mitochondrial fractions}

From dissected mussels, the digestive glands (hepatopancreas) were quickly removed, pooled (10-15 animals for each pool), repeatedly rinsed in ice-cold medium A $(0.25 \mathrm{M}$ sucrose, $5 \mathrm{mM}$ 
Tris(hydroxymethyl)-aminomethane (Tris), $5 \mathrm{mM}$ ethylenediammine tetraacetic acid (EDTA), pH 7.4) and gently dried on blotting paper. Whenever detected, the crystalline stylus was promptly removed. Then tissues were weighted and stored in small vials in small amounts of medium A in liquid nitrogen until use. Immediately after thawing, excess medium was decanted and the digestive glands were homogenized in medium $B(0.25 \mathrm{mM}$ sucrose, $0.5 \mathrm{~g} / \mathrm{L}$ fatty acid-free bovine serum albumin (BSA), Tris $24 \mathrm{mM}, \mathrm{pH}$ 7.4), in the proportion $11 \mathrm{~mL}$ medium $\mathrm{B}$ for each $\mathrm{g}$ (wet mass) of tissue, by Braun homogenizer Type 853202 at $450 \mathrm{rpm}$ for $1 \mathrm{~min}$. The mitochondrial fraction was obtained by stepwise centrifugation (Sorvall RC2-B, rotor SS34). The homogenate was centrifuged at 1,100xg for $8 \mathrm{~min}$; the obtained supernatant was filtered through four gauze layers and further centrifuged at 16,800xg for 10 min to yield the raw mitochondrial pellet. The latter was resuspended in medium B and further centrifuged at the same speed for $10 \mathrm{~min}$ to obtain the final mitochondrial pellet which was resuspended by gentle stirring using a Teflon Potter Elvejehm homogenizer in a small volume of medium B, thus obtaining a protein concentration of $10-12 \mathrm{mg} / \mathrm{mL}$. All steps were carried out at $0-4{ }^{\circ} \mathrm{C}$. Protein concentration was determined by Bio-Rad Protein Assay kit II with BSA as standard according to the colorimetric method of Bradford [30]. Mitochondrial preparations were then stored in liquid nitrogen until use. The stability of mitochondrial preparations in liquid nitrogen was previously evaluated as a function of storage time. Results indicated that the mitochondrial Mg-ATPase activity was unaffected even after a year [31].

Prior to storage, the respiratory activities were polarographically evaluated [32] on freshly prepared mitochondrial membranes as previously described [33], to check their functionality. These tests, combined with the failed detection of the Na,K-ATPase activity, a known marker of plasma membranes [34], witnessed the quality and the virtual absence of contamination of mitochondrial preparations [35].

\subsection{Mitochondrial $F_{1} F_{O}$-ATPase activity assays}

Immediately after thawing, mitochondrial preparations were used to evaluate the $\mathrm{F}_{1} \mathrm{~F}_{\mathrm{O}}$-ATPase activity. The ATP hydrolysis capability was assayed in a reaction medium $(1 \mathrm{~mL})$ containing 0.15 $\mathrm{mg}$ mitochondrial protein and $75 \mathrm{mM}$ ethanolammine- $\mathrm{HCl}$ buffer $\mathrm{pH}$ 8.9, $5.0 \mathrm{mM} \mathrm{Na} 2 \mathrm{ATP}$ and 2.0 $\mathrm{mM} \mathrm{MgCl} 2$ for the $\mathrm{Mg}^{2+}$-activated $\mathrm{FF}_{1} \mathrm{Fo}_{\mathrm{O}}$-ATPase assay, and in the same buffer at $\mathrm{pH} 8.9$ plus 5.0 $\mathrm{mM} \mathrm{Na} 2 \mathrm{ATP}$ and $2.0 \mathrm{mM} \mathrm{CaCl}_{2}$ to evaluate the $\mathrm{Ca}^{2+}$-activated $\mathrm{F}_{1} \mathrm{Fo}_{\mathrm{O}}$-ATPase activity. After $5 \mathrm{~min}$ preincubation at $30{ }^{\circ} \mathrm{C}$, the reaction, carried out at the same temperature, was started by adding the substrate $\mathrm{Na}_{2} \mathrm{ATP}$ and stopped after $5 \mathrm{~min}$ by adding $1 \mathrm{~mL}$ of ice-cold $15 \%(\mathrm{w} / \mathrm{w})$ trichloroacetic acid aqueous solution. Once the reaction was blocked, vials were centrifuged for $15 \mathrm{~min}$ at 3,500 rpm 
(Eppendorf Centrifuge 5202). The concentration of inorganic phosphate (Pi) hydrolyzed by known amounts of mitochondrial protein in the supernatant, which indirectly detects the $\mathrm{F}_{1} \mathrm{~F}_{\mathrm{O}}$-ATPase activity, was spectrophotometrically evaluated [36]. To this aim, $1.0 \mu \mathrm{L}$ from a stock solution of 4.0 $\mathrm{mg} / \mathrm{mL}$ oligomycin in dimethylsulfoxide (DMSO) was directly added to the reaction mixture before starting the reaction. The total $\mathrm{F}_{1} \mathrm{~F}_{\mathrm{O}}$-ATPase activity was calculated by the Pi evaluation in control tubes run in parallel and containing 1.0 $\mu \mathrm{L}$ DMSO per mL reaction system. Control tubes were alternated to the condition to be tested in each set of experiments. The dose of $4.0 \mathrm{mg} / \mathrm{mL}$ oligomycin, specific inhibitor of $\mathrm{F}_{1} \mathrm{~F}_{\mathrm{O}}$-ATPase, which selectively blocks the $\mathrm{F}_{0}$ subunit, which is currently used in $\mathrm{F}_{1} \mathrm{~F}_{\mathrm{O}}$-ATPase assays [37], ensured maximal $\mathrm{F}_{1} \mathrm{~F}_{\mathrm{O}}$-ATPase inhibition. The $\mathrm{F}_{1} \mathrm{~F}_{\mathrm{O}}$-ATPase activity, also defined as mitochondrial oligomycin-sensitive ATPase activity, was routinely measured by subtracting, from the Pi hydrolyzed by total mitochondrial ATPase activity, the Pi hydrolyzed in the presence of oligomycin (mitochondrial oligomycin-insensitive ATPase), and expressed as $\mu \mathrm{mol}$ Pi.mg protein ${ }^{-1} \cdot \mathrm{min}^{-1}$ in all experiments. Even if the mitochondrial ATPase activity in mussels referred to $\mathrm{F}_{1} \mathrm{~F}_{\mathrm{O}}$-ATPase could be only confirmed by SDS-gel and Western Blot analyses, the ways to confirm enzyme purity and integrity as done in E. coli $\mathrm{F}_{1} \mathrm{~F}_{\mathrm{O}}$-ATP synthase by other lab [38], at present we could not do it, due to the lack of adequate protocol and reagents.

The effects of the NaHS were tested by adding $4 \mu \mathrm{l}$ aliquots of NaHS in DMSO (control in NaHSfree medium with $4 \mu \mathrm{l}$ DMSO) to the reaction mixture immediately prior to the addition of the mitochondrial suspensions. To this aim, NaHS concentrations, obtained by dilution from the $25 \mathrm{mM}$ NaHS DMSO stock solution, were added to the reaction mixture to obtain final NaHS concentrations in the range $0.1-100 \mu \mathrm{M}$ NaHS in the reaction system.

\subsection{Kinetic analyses}

In all plots the specific enzyme activity, evaluated as $\mu$ moles $\mathrm{P}_{\mathrm{i}} \cdot \mathrm{mg}$ protein ${ }^{-1} \mathrm{~min}^{-1}$ was taken as the expression of the initial reaction rate $v$. To evaluate the enzyme activation kinetics by the ATP substrate, Hill plots were built [39]. To this aim $\mathrm{Mg}^{2+}$ and $\mathrm{Ca}^{2+}$-ATPase assays were carried out at various stated ATP millimolar concentrations in the reaction medium, by keeping constant all other assay conditions. The linear transformation of Hill equation was used:

$$
\log \frac{v_{0}}{V_{\max }-v_{0}}=-n_{H i} \log [A T P]+\log K^{\prime}
$$

where $V_{\max }$ and $v_{0}$ represent the enzyme reaction rates, respectively in the presence of substrate concentration which gives the maximal rate and in the presence of a stated substrate concentration 
$[A T P], K^{\prime}$ is a constant value. By plotting $\log v_{0} /\left(V_{\max }-v_{0}\right)$ versus $\log [A T P]$ a straight line is obtained, whose slope is Hill coefficient $\left(-n_{H i}\right)$. In case $\left|n_{H i}\right| \neq 1$ multiple binding sites for the substrate can be involved [39] even if the $n_{H i}$ value cannot stoichiometrically correspond to the binding sites.

To calculate the kinetic parameters $\left(V_{\max }\right.$ and $\left.K_{\mathrm{m}}\right)$ in the presence of different concentrations of ATP substrate, enzyme activity data were fitted to the Lineweaver-Burk equation in which the reciprocal of the reaction rate $(1 / v)$ was plotted as a function of the reciprocal concentration of ATP, raised to a power $\left(n_{H i}\right)$ which corresponds to Hill coefficient. This corrective procedure allows the building of a linear Lineweaver-Burk plot, and consequently the calculation of $V_{\max }$ and $K_{\mathrm{m}}$ values from the intercept with $y$ and $x$ axis, respectively, even when $n_{H i}$ is $\neq 1$.

Correlation coefficients were never lower than 0.96 thus confirming the linearity of all plots.

\section{6. mPTP assay}

Immediately after the preparation of mussel midgut gland mitochondrial fractions, fresh mitochondrial suspensions $(1 \mathrm{mg} / \mathrm{mL})$ were energized in the assay buffer $(130 \mathrm{mM} \mathrm{KCl}, 1 \mathrm{mM}$ $\mathrm{KH}_{2} \mathrm{PO}_{4}, 20 \mathrm{mM}$ HEPES, pH 7.2 with TRIS), incubated at $30^{\circ} \mathrm{C}$ with $1 \mu \mathrm{g} / \mathrm{mL}$ rotenone and $5 \mathrm{mM}$ succinate. To evaluate NaHS effect, selected NaHS doses were added to the mitochondrial suspensions before mPTP evaluation. mPTP opening was induced by the addition of low concentrations of $\mathrm{Ca}^{2+}(10 \mu \mathrm{M})$ as $\mathrm{CaCl}_{2}$ solution at fixed time intervals (1 min). The calcium retention capacity (CRC), whose lowering indicates mPTP opening, was spectrofluorophotometrically evaluated in the presence of $0.8 \mu \mathrm{M}$ Fura-FF. The probe has different spectral properties in the absence and in the presence of $\mathrm{Ca}^{2+}$, namely it displays excitation/emission spectra of $365 / 514 \mathrm{~nm}$ in the absence of $\mathrm{Ca}^{2+}$ (Fura-FF low $\mathrm{Ca}^{2+}$ ) and shifts to $339 / 507 \mathrm{~nm}$ in the presence of high $\mathrm{Ca}^{2+}$ concentrations (Fura-FF high $\mathrm{Ca}^{2+}$ ). mPTP opening, was evaluated by the increase in the fluorescence intensity ratio (Fura-FF high $\left.\mathrm{Ca}^{2+}\right) /\left(\mathrm{Fura}_{-\mathrm{FF}}\right.$ low $\left.\mathrm{Ca}^{2+}\right)$, which indicates a decrease in CRC [40]. All measurements were processed by LabSolutions RF software.

\subsection{Calculations and statistics}

Statistical analyses were performed by SIGMASTAT software. The analysis of variance followed by Students-Newman-Keuls' test when $\mathrm{F}$ values indicated significance $(P \leq 0.05)$ was applied. Percentage data were arcsin-transformed before statistical analyses to ensure normality. 


\section{Results and discussion}

\section{1. $\mathrm{Ca}^{2+}$ - and $\mathrm{Mg}^{2+}$-dependent $\mathrm{F}_{1} \mathrm{~F}_{\mathrm{O}}$-ATPase kinetic parameters}

As first approach, experiments aimed at pointing out the kinetic properties of the $\mathrm{F}_{1} \mathrm{~F}_{\mathrm{O}}$-ATPase in mussel digestive gland mitochondria either activated by the natural cofactor $\mathrm{Mg}^{2+}$ or by $\mathrm{Ca}^{2+}$, being the latter involved in the lethal task of triggering the mPTP formation [14,40,41]. The $\mathrm{F}_{1} \mathrm{~F}_{\mathrm{O}}$-ATPase energy transduction mechanism converts the electrochemical gradient of a transmembrane proton motive force $(\Delta p)$ by torque generation into ATP chemical energy during ATP synthesis and vice versa by ATP hydrolysis [42]. Both enzyme tasks of ATP synthesis/hydrolysis are sustained by the natural cofactor $\mathrm{Mg}^{2+}$ or by other metal divalent cations $[14,43,44]$. However, $\mathrm{Ca}^{2+}$ only sustains ATP synthesis and in this case, the rotor rotation was reported to be not coupled to $\Delta p$ generation in beef heart submitochondrial particles [43], in Rhodospirillum rubrum [45], in chloroplast thylakoids [46] and in pea stem mitochondria [47]. Conversely, ATP complexed with $\mathrm{Ca}^{2+}$ can drive the $\mathrm{pH}$ gradient formation with nearly the same effectiveness as MgATP in Escherichia coli [48]. Moreover, in swine heart submitochondrial particles the $\mathrm{Ca}^{2+}$-dependent $\mathrm{F}_{1} \mathrm{~F}_{\mathrm{O}}$-ATPase is inhibited by succinate- $\mathrm{O}_{2}$ oxidoreductase activity, which generating the $\Delta p$ contrast the $\mathrm{H}^{+}$-pumping $\mathrm{F}_{1} \mathrm{~F}_{\mathrm{O}}$-ATPase. On the other hand, dinitrophenol makes the submitochondrial particles membrane permeable to $\mathrm{H}^{+}$and increases the hydrolytic activity of the $\mathrm{Ca}^{2+}$-dependent $\mathrm{F}_{1} \mathrm{~F}_{\mathrm{O}}$-ATPase coupled to $\mathrm{H}^{+}$pumping [13]. The $\mathrm{Ca}^{2+}$ dependent $\mathrm{F}_{1} \mathrm{~F}_{\mathrm{O}}$-ATPase of swine heart [13] and pea stem mitochondria [47] are fully sensitive to oligomycin, a specific inhibitor of $F_{O}$ domain [49]. In mussel midgut gland mitochondria ATP hydrolysis can be sustained by $\mathrm{Ca}^{2+}$, other than by $\mathrm{Mg}^{2+}$, even if the oligomycin-sensitive ATPase activity only represents the $40 \%$ of total ATPase activity, while in presence of $\mathrm{Mg}^{2+}$ the oligomycin sensitive ATPase is as much as $85 \%$ of the total ATPase activity (Fig. 1). Moreover, the coupling index calculated as mitochondrial oligomycin-sensitive ATPase activity on the total mitochondrial ATPase activity ratio of the $\mathrm{Mg}^{2+}$-dependent $\mathrm{F}_{1} \mathrm{FO}_{\mathrm{O}}$-ATPase shows a better value than the $\mathrm{Ca}^{2+}$ dependent $\mathrm{F}_{1} \mathrm{~F}_{\mathrm{O}}$-ATPase $(0.85 \pm 0.13$ vs $0.37 \pm 0.08)$. Since we do not have the protocol for $\mathrm{F}_{1} \mathrm{~F}_{\mathrm{O}}$ ATPase isolation and purification from mussel mitochondria, the results obtained refer to the $\mathrm{F}_{1} \mathrm{~F}_{\mathrm{O}}$ ATPase activity in isolated mitochondria.

Further experiments aimed at casting light on the enzyme kinetics, a quite unexplored field in mussel mitochondria. The binding change mechanism for the $\mathrm{F}_{1}$-ATPase [50] is known to be sustained by positive cooperativity of three catalytic sites. The ATP substrate can simultaneously fill from one to three sites during the catalysis denoting it as uni-site, bi-site, or tri-site catalysis, respectively. The rate of ATP hydrolysis is ATP concentration dependent. Steady-state catalysis studies provide evidence that the main kinetic enhancement occurs by bi-site activation inducing strong positive 
cooperativity [51]. The mussel midgut gland $\mathrm{F}_{1} \mathrm{~F}_{\mathrm{O}}-\mathrm{ATPase}$ activated by $\mathrm{Mg}^{2+}$ or $\mathrm{Ca}^{2+}$ show similar Hill coefficients, namely $1.72 \pm 0.20$ and $1.71 \pm 0.22$ respectively (Fig. $2 \mathrm{~A}, \mathrm{~B}$ ), thus suggesting that, in both cases, ATP can also bind to a two catalytic sites to yield high rates of catalysis. However, $\mathrm{Mg}^{2+}$ and $\mathrm{Ca}^{2+}$ do not sustain ATP hydrolysis by the $\mathrm{F}_{1} \mathrm{~F}_{\mathrm{O}}$-ATPase with the same efficiency. Accordingly, even if the $K_{\mathrm{m}}$ values are similar for the two differently activated ATPases, the $\mathrm{Mg}^{2+}$-activated $\mathrm{F}_{1} \mathrm{~F}_{\mathrm{O}^{-}}$ ATPase shows a $57 \%$ higher $V_{\max }$ value than the $\mathrm{Ca}^{2+}$-activated enzyme (Fig. 2C,D), which indicates that, when activated by $\mathrm{Mg}^{2+}$, the enzyme hydrolytic activity is more efficient, as in mammals $[13,14]$. On this basis, the mussel oligomycin-sensitive $\mathrm{Ca}^{2+}$-dependent $\mathrm{F}_{1} \mathrm{~F}_{\mathrm{O}}$-ATP(hydrol)ase could be enlisted in the mitochondrial bioenergetic regulation machinery, since its affinity for ATP is the same as the companion $\mathrm{Mg}^{2+}$-activated enzyme.

\subsection{NaHS effect on the mitochondrial $F_{1} F_{O}$-ATPases and permeability transition pore}

Since mussel midgut gland mitochondria contain an ATPase activity that can be activated by both $\mathrm{Mg}^{2+}$ and $\mathrm{Ca}^{2+}$ with different kinetic properties, it seemed interesting to evaluate the effect of the sulfide donor NaHS on these enzyme activities and to search for a putative connection with the mPTP. NaHS is widely used to generate $\mathrm{H}_{2} \mathrm{~S}$, which, once only known as mitochondrial poison, in recent years has raised increasing interest in cell biology as endogenous gaseous neurotransmitter [52] that acts on cardiovascular system and inflammation as well as on nervous systems, pain appreciation, gastrointestinal and urogenital functions, and endocrine system [53]. The effect, deleterious or on the contrary beneficial, apparently depends on the dose and on the microenvironmental conditions, which in turn include a number of variables. Accordingly, $\mathrm{NaHS}$ and related compounds $\mathrm{H}_{2} \mathrm{~S}, \mathrm{HS}^{-}$and $\mathrm{S}^{2-}$, can also alter the function of cellular proteins and enzymes by inducing post-translational modifications especially on "redox sensor" cysteines [54]. In mammalian mitochondria the $\alpha$ subunits of $\mathrm{F}_{1} \mathrm{~F}_{\mathrm{O}}$-ATPase, involved in the catalytic and non-catalytic sites of $\mathrm{F}_{1}$ domain [55], show cysteine residues at positions 244 and 294 prone to reversible $S$-sulfhydration [56]. Modification of thiol ($\mathrm{SH}$ ) group of cysteines by covalent bond to $\mathrm{H}_{2} \mathrm{~S}$ forms persulfide (-SSH) group [11]. Other than acting as a mitochondrial poison when blocks complex IV, sulfide can stimulate the ATP synthase by inducing $S$-sulfhydration of $\alpha$ subunits in a concentration-dependent manner [56]. The increase in the enzyme catalytic mechanism when the $\alpha \mathrm{Cys} 244$ and $\alpha \mathrm{Cys} 294$ are $S$-sulfhydrized under (patho)physiological conditions prevents the disulfide bond formation under oxidative stress conditions, which forms before the individual subunits (e.g. $\alpha$ and $\gamma$ subunits) assemble into the ATP synthase complex [57] and alters the $\mathrm{F}_{1}$-ATPase chemomechanical mechanism [58]. However, quite surprisingly, when increasing NaHS concentrations are tested on mussel midgut gland mitochondria, 
no effect on the $\mathrm{Ca}^{2+}$ - and $\mathrm{Mg}^{2+}$-activated $\mathrm{F}_{1} \mathrm{~F}_{\mathrm{O}}$-ATPases is shown (Fig. 3). Although in eukaryotes there is a high similarity of amino acid sequences in the $\mathrm{F}_{1} \mathrm{~F}_{\mathrm{O}}$-ATPase subunits [59], the mussel $\mathrm{F}_{1} \mathrm{~F}_{\mathrm{O}}$ ATPase cysteines may be refractory to covalently bind to sulfide. Both mPTP and oxidative stress are known to be inhibited by exogenous $\mathrm{H}_{2} \mathrm{~S}$ that acts as a cell death modulator [60]. The role of $\mathrm{Ca}^{2+}$ in the PTP opening has also been associated with the interaction with phospholipids of the inner mitochondrial membranes where it appears to induce changes in cardiolipin (CL) packing and to increase CL susceptibility to oxidation [61]. On these bases, the peculiar CL molecular species of mussel, dominated by an extraordinary high level of 22:6n-3 exceeding $70 \%$ of total fatty acids [62] and identified as predominantly in a form with four docosahexaenoyl chains and thus easily exposed to oxidation, can help to explain the different regulation mechanisms in different taxa. The $\mathrm{F}_{1} \mathrm{~F}_{\mathrm{O}}$ ATPase is the molecular architecture proposed to coincide with the MPTP [63-65]. Recently two conformations with low and high ion-conductance have been attributed to the monomeric or dimeric form of the $\mathrm{F}_{1} \mathrm{~F}_{\mathrm{O}}$-ATPase $[15,16]$ in presence of $\mathrm{Ca}^{2+}$. Other membrane-embedded protein of IMM as adenine nucleotide translocase, could only sustain the low ion-conductance that is $\mathrm{Ca}^{2+}$-dependent and bongkrekic acid sensitive [16,66]. Even if the existence of mPTP is still elusive in mussels, the detection of the $\mathrm{Ca}^{2+}$-activated $\mathrm{F}_{1} \mathrm{~F}_{\mathrm{O}}$-ATP(hydrol)ase, which was shown to most likely coincide with the mPTP $[14,41]$, strongly suggests that mussel midgut gland mitochondria possess MPTP activity whose responsiveness to sulfide was tested. Accordingly, in mussel midgut gland mitochondria the CRC decreases at increasing $\mathrm{Ca}^{2+}$ concentrations (Fig. 4). The NaHS treatment desensitizes the mPTP activity, even if it is ineffective on the $\mathrm{Ca}^{2+}$-activated $\mathrm{F}_{1} \mathrm{FO}_{\mathrm{O}}$-ATPase (Fig. 3). Experiments carried out by adding to mitochondria the mitochondrial calcium uniporter inhibitor Ruthenium Red result in similar CRC profiles in response to subsequent $10 \mu \mathrm{M} \mathrm{CaCl}_{2}$ pulses in the presence of 50 and 100 $\mu \mathrm{M}$ NaHS and of $1 \mu \mathrm{M}$ Ruthenium Red. Regulatory role of CL can extend to adenine nucleotide translocase which constitute regulatory component of mPTP [16]. So, the $\mathrm{Ca}^{2+}$ uptake by mitochondria is clearly affected by NaHS (Fig. 4) and, as a consequence the mPTP, is desensitized, namely it requires higher $\mathrm{Ca}^{2+}$ load to open and release the cation.

\section{Conclusions}

Some main observations can be drawn from the results of the present study. First, mussel midgut gland mitochondria contain an oligomycin-sensitive $\mathrm{F}_{1} \mathrm{~F}_{\mathrm{O}}$-ATPase activity that can be activated either by $\mathrm{Mg}^{2+}$ or by $\mathrm{Ca}^{2+}$, as in mammals. Both $\mathrm{F}_{1} \mathrm{~F}_{\mathrm{O}}$-ATPase activity are coupled, as revealed by the extent of oligomycin sensitivity. However, some differences exist between molluscan and mammalian $\mathrm{F}_{1} \mathrm{~F}_{\mathrm{O}}$ ATPases revealed by the sulfide responsiveness. Second, mussel mitochondria are able to form the 
mPTP. However, the connection between the $\mathrm{Ca}^{2+}$-dependent $\mathrm{F}_{1} \mathrm{~F}_{\mathrm{O}}$-ATPase and the mPTP is weakened in these invertebrates, since $\mathrm{NaHS}$, at least under the experimental conditions adopted, has no effect on the enzyme activity even if it inhibits the mPTP. Moreover, if, on the one hand, the "mussel model" to deepen studies on mitochondria is strengthened, due to some kinetic similarities with mammals and the easy-to-use biological material, on the other hand the hypothesis that the mPTP regulation, and perhaps the same mPTP role, may be different in different taxa, is somehow shouldered. The mPTP responsiveness to sulfide in the mussel opens a new scenario to be investigated. Among the still unsolved questions, it remains unclear if sulfide can interact with other proteins involved in $\mathrm{Ca}^{2+}$ homeostasis and if the $\mathrm{F}_{1} \mathrm{~F}_{\mathrm{O}}$-ATPase refractoriness can physiologically play a protective role in sulfide-rich environments. Accordingly, some sulfide-driven post-translational modifications of proteins are irreversible and can produce permanent damage to the biostructures. In this perspective the chemical un-reactivity of the bioenergetic mechanisms can be even advantageous for mussels.

\section{Funding}

This work was financed by the University of Bologna, Italy (Almaidea senior grant to AP).

\section{Author contributions}

$\mathrm{CA}, \mathrm{SN}$ and MF carried out the experiments; SN planned the experimental design and supervised the experiments, SN and AP wrote the manuscript; AP VV and FT revised the text; AP funding acquisition; all authors read and approved the final text.

\section{References}

[1] R. Wang, Physiological implications of hydrogen sulfide: a whiff exploration that blossomed, Physiol. Rev. 92 (2012) 791-896. https://doi.org/10.1152/physrev.00017.2011.

[2] D.-D. Wu, D.-Y. Wang, H.-M. Li, J.-C. Guo, S.-F. Duan, X.-Y. Ji, Hydrogen Sulfide as a Novel Regulatory Factor in Liver Health and Disease, Oxid Med Cell Longev. 2019 (2019) 3831713. https://doi.org/10.1155/2019/3831713.

[3] D.W. Kraus, J.E. Doeller, Sulfide consumption by mussel gill mitochondria is not strictly tied to oxygen reduction: measurements using a novel polarographic sulfide sensor, J. Exp. Biol. 207 (2004) 36673679. https://doi.org/10.1242/jeb.01212.

[4] J. Bettowski, Synthesis, Metabolism, and Signaling Mechanisms of Hydrogen Sulfide: An Overview, Methods Mol. Biol. 2007 (2019) 1-8. https://doi.org/10.1007/978-1-4939-9528-8_1.

[5] T. Bagarinao, Sulfide as an environmental factor and toxicant: tolerance and adaptations in aquatic organisms, Aquatic Toxicology. 24 (1992) 21-62. https://doi.org/10.1016/0166-445X(92)90015-F. 
[6] G.K. Kolluru, X. Shen, S.C. Bir, C.G. Kevil, Hydrogen sulfide chemical biology: pathophysiological roles and detection, Nitric Oxide. 35 (2013) 5-20. https://doi.org/10.1016/j.niox.2013.07.002.

[7] R. Wedmann, S. Bertlein, I. Macinkovic, S. Böltz, J.L. Miljkovic, L.E. Muñoz, M. Herrmann, M.R. Filipovic, Working with "H2S": facts and apparent artifacts, Nitric Oxide. 41 (2014) 85-96. https://doi.org/10.1016/j.niox.2014.06.003.

[8] S.L. Malone Rubright, L.L. Pearce, J. Peterson, Environmental toxicology of hydrogen sulfide, Nitric Oxide. 71 (2017) 1-13. https://doi.org/10.1016/j.niox.2017.09.011.

[9] B. Murphy, R. Bhattacharya, P. Mukherjee, Hydrogen sulfide signaling in mitochondria and disease, FASEB J. 33 (2019) 13098-13125. https://doi.org/10.1096/fj.201901304R.

[10] T.V. Mishanina, M. Libiad, R. Banerjee, Biogenesis of reactive sulfur species for signaling by hydrogen sulfide oxidation pathways, Nat. Chem. Biol. 11 (2015) 457-464. https://doi.org/10.1038/nchembio.1834.

[11] E. Cuevasanta, M.N. Möller, B. Alvarez, Biological chemistry of hydrogen sulfide and persulfides, Arch. Biochem. Biophys. 617 (2017) 9-25. https://doi.org/10.1016/j.abb.2016.09.018.

[12] S. Nesci, Mitochondrial permeability transition, $\mathrm{F}_{1} \mathrm{~F}_{\mathrm{O}}-\mathrm{ATPase}$ and calcium: an enigmatic triangle, EMBO Rep. 18 (2017) 1265-1267. https://doi.org/10.15252/embr.201744570.

[13] S. Nesci, F. Trombetti, V. Ventrella, M. Pirini, A. Pagliarani, Kinetic properties of the mitochondrial F1FO-ATPase activity elicited by $\mathrm{Ca}(2+)$ in replacement of $\mathrm{Mg}(2+)$, Biochimie. 140 (2017) 73-81. https://doi.org/10.1016/j.biochi.2017.06.013.

[14] C. Algieri, F. Trombetti, A. Pagliarani, V. Ventrella, C. Bernardini, M. Fabbri, M. Forni, S. Nesci, Mitochondrial Ca2+-activated F1 FO -ATPase hydrolyzes ATP and promotes the permeability transition pore, Ann. N. Y. Acad. Sci. 1457 (2019) 142-157. https://doi.org/10.1111/nyas.14218.

[15] A. Urbani, V. Giorgio, A. Carrer, C. Franchin, G. Arrigoni, C. Jiko, K. Abe, S. Maeda, K. Shinzawa-Itoh, J.F.M. Bogers, D.G.G. McMillan, C. Gerle, I. Szabò, P. Bernardi, Purified F-ATP synthase forms a Ca2+dependent high-conductance channel matching the mitochondrial permeability transition pore, Nat Commun. 10 (2019) 4341. https://doi.org/10.1038/s41467-019-12331-1.

[16] N. Mnatsakanyan, M.C. Llaguno, Y. Yang, Y. Yan, J. Weber, F.J. Sigworth, E.A. Jonas, A mitochondrial megachannel resides in monomeric F1FO ATP synthase, Nat Commun. 10 (2019) 5823. https://doi.org/10.1038/s41467-019-13766-2.

[17] C. Konràd, G. Kiss, B. Töröcsik, J.L. Lábár, A.A. Gerencser, M. Mándi, V. Adam-Vizi, C. Chinopoulos, A distinct sequence in the adenine nucleotide translocase from Artemia franciscana embryos is associated with insensitivity to bongkrekate and atypical effects of adenine nucleotides on Ca2+ uptake and sequestration, FEBS J. 278 (2011) 822-836. https://doi.org/10.1111/j.1742-4658.2010.08001.x.

[18] C. Chinopoulos, Mitochondrial permeability transition pore: Back to the drawing board, Neurochem. Int. 117 (2018) 49-54. https://doi.org/10.1016/j.neuint.2017.06.010.

[19] E. Torrezan-Nitao, R.C.B.Q. Figueiredo, L.F. Marques-Santos, Mitochondrial permeability transition pore in sea urchin female gametes, Mech. Dev. 154 (2018) 208-218. https://doi.org/10.1016/j.mod.2018.07.008.

[20] C.M. Hickey, J.E. Geiger, C.J. Groten, N.S. Magoski, Mitochondrial Ca2+ activates a cation current in Aplysia bag cell neurons, J. Neurophysiol. 103 (2010) 1543-1556. https://doi.org/10.1152/jn.01121.2009.

[21] C. Konrad, G. Kiss, B. Torocsik, V. Adam-Vizi, C. Chinopoulos, Absence of Ca2+-induced mitochondrial permeability transition but presence of bongkrekate-sensitive nucleotide exchange in C. crangon and $\mathrm{P}$. serratus, PLoS ONE. 7 (2012) e39839. https://doi.org/10.1371/journal.pone.0039839.

[22] P. Bernardi, A. Rasola, M. Forte, G. Lippe, The Mitochondrial Permeability Transition Pore: Channel Formation by F-ATP Synthase, Integration in Signal Transduction, and Role in Pathophysiology, Physiol. Rev. 95 (2015) 1111-1155. https://doi.org/10.1152/physrev.00001.2015.

[23] S. Nesci, V. Ventrella, F. Trombetti, M. Pirini, A. Pagliarani, Mussel and mammalian ATP synthase share the same bioenergetic cost of ATP, J. Bioenerg. Biomembr. 45 (2013) 289-300. https://doi.org/10.1007/s10863-013-9504-1.

[24] P.S. Wilson, K. Vopel, Assessing the Sulfide Footprint of Mussel Farms with Sediment Profile Imagery: A New Zealand Trial, PLoS ONE. 10 (2015) e0129894. https://doi.org/10.1371/journal.pone.0129894. 
[25] C. Walker, S.A. Böttger, J. Mulkern, E. Jerszyk, M. Litvaitis, M. Lesser, Mass culture and characterization of tumor cells from a naturally occurring invertebrate cancer model: applications for human and animal disease and environmental health, Biol. Bull. 216 (2009) 23-39.

https://doi.org/10.1086/BBLv216n1p23.

[26] X. Sun, Z. Liu, B. Wu, L. Zhou, Q. Wang, W. Wu, A. Yang, Differences between fast and slow muscles in scallops revealed through proteomics and transcriptomics, BMC Genomics. 19 (2018) 377. https://doi.org/10.1186/s12864-018-4770-2.

[27] S. Kapoor, N. Nailwal, M. Kumar, K. Barve, Recent Patents and Discovery of Anti-inflammatory Agents from Marine Source, Recent Pat Inflamm Allergy Drug Discov. 13 (2019) 105-114. https://doi.org/10.2174/1872213X13666190426164717.

[28] D. Munro, P.U. Blier, The extreme longevity of Arctica islandica is associated with increased peroxidation resistance in mitochondrial membranes, Aging Cell. 11 (2012) 845-855. https://doi.org/10.1111/j.1474-9726.2012.00847.x.

[29] N.E. Moyen, G.N. Somero, M.W. Denny, Impact of heating rate on cardiac thermal tolerance in the California mussel, Mytilus californianus, J. Exp. Biol. 222 (2019). https://doi.org/10.1242/jeb.203166.

[30] M.M. Bradford, A rapid and sensitive method for the quantitation of microgram quantities of protein utilizing the principle of protein-dye binding, Anal. Biochem. 72 (1976) 248-254.

[31] A. Pagliarani, P. Bandiera, V. Ventrella, F. Trombetti, M. Pirini, S. Nesci, A.R. Borgatti, Tributyltin (TBT) inhibition of oligomycin-sensitive Mg-ATPase activity in mussel mitochondria, Toxicol In Vitro. 22 (2008) 827-836. https://doi.org/10.1016/j.tiv.2007.12.015.

[32] B. Chance, G.R. Williams, The respiratory chain and oxidative phosphorylation, Adv Enzymol Relat Subj Biochem. 17 (1956) 65-134. https://doi.org/10.1002/9780470122624.ch2.

[33] S. Nesci, V. Ventrella, F. Trombetti, M. Pirini, A. Pagliarani, Tri-n-butyltin binding to a low-affinity site decreases the F 1F O-ATPase sensitivity to oligomycin in mussel mitochondria, Applied Organometallic Chemistry. 26 (2012) 593-599. https://doi.org/10.1002/aoc.2904.

[34] A. Pagliarani, P. Bandiera, V. Ventrella, F. Trombetti, M.P. Manuzzi, M. Pirini, A.R. Borgatti, Response of $\mathrm{Na}(+)$-dependent ATPase activities to the contaminant ammonia nitrogen in Tapes philippinarum: possible atpase involvement in ammonium transport, Arch. Environ. Contam. Toxicol. 55 (2008) 49-56. https://doi.org/10.1007/s00244-007-9102-5.

[35] V. Ventrella, S. Nesci, F. Trombetti, P. Bandiera, M. Pirini, A.R. Borgatti, A. Pagliarani, Tributyltin inhibits the oligomycin-sensitive Mg-ATPase activity in Mytilus galloprovincialis digestive gland mitochondria, Comp. Biochem. Physiol. C Toxicol. Pharmacol. 153 (2011) 75-81. https://doi.org/10.1016/j.cbpc.2010.08.007.

[36] S. Nesci, F. Trombetti, M. Pirini, V. Ventrella, A. Pagliarani, Mercury and protein thiols: Stimulation of mitochondrial F1FO-ATPase and inhibition of respiration, Chem. Biol. Interact. 260 (2016) 42-49. https://doi.org/10.1016/j.cbi.2016.10.018.

[37] S. Nesci, V. Ventrella, F. Trombetti, M. Pirini, A. Pagliarani, Multi-site TBT binding skews the inhibition of oligomycin on the mitochondrial Mg-ATPase in Mytilus galloprovincialis, Biochimie. 93 (2011) 11571164. https://doi.org/10.1016/j.biochi.2011.04.008.

[38] S. Raheem, A. Steiner, Z. Ahmad, Functional importance of $\alpha$ Asp-350 in the catalytic sites of Escherichia coli ATP synthase, Arch Biochem Biophys. 672 (2019) 108050. https://doi.org/10.1016/j.abb.2019.07.015.

[39] I.H. Segel, Enzyme Kinetics, in: W.J. Lennarz, M.D. Lane (Eds.), Encyclopedia of Biological Chemistry, Academic Press, Waltham, 2013: pp. 216-220. https://doi.org/10.1016/B978-0-12-378630-2.00012-8.

[40] C. Algieri, F. Trombetti, A. Pagliarani, V. Ventrella, S. Nesci, Phenylglyoxal inhibition of the mitochondrial F1FO-ATPase activated by $\mathrm{Mg} 2+$ or by $\mathrm{Ca} 2+$ provides clues on the mitochondrial permeability transition pore, Arch. Biochem. Biophys. 681 (2020) 108258. https://doi.org/10.1016/j.abb.2020.108258.

[41] Vincenzo Algieri, Cristina Algieri, Loredana Maiuolo, Antonio De Nino, Alessandra Pagliarani, Matteo A. Tallarida, Fabiana Trombetti, Salvatore Nesci, 1,5-Disubstituted-1,2,3-triazoles as inhibitors of the mitochondrial Ca2+-activated F1FO-ATP(hydrol)ase and of the permeability transition pore, Ann. N. Y. Acad. Sci. (2020). https://doi.org/10.1111/nyas.14474. 
[42] S. Nesci, A. Pagliarani, C. Algieri, F. Trombetti, Mitochondrial F-type ATP synthase: multiple enzyme functions revealed by the membrane-embedded FO structure, Crit. Rev. Biochem. Mol. Biol. 55 (2020) 309-321. https://doi.org/10.1080/10409238.2020.1784084.

[43] S. Papageorgiou, A.B. Melandri, G. Solaini, Relevance of divalent cations to ATP-driven proton pumping in beef heart mitochondrial FOF1-ATPase, J. Bioenerg. Biomembr. 30 (1998) 533-541.

[44]Z. Gromet-Elhanan, S. Weiss, Regulation of .DELTA. .mu.H + -coupled ATP synthesis and hydrolysis: role of divalent cations and of the FOF1-.beta. subunit, Biochemistry. 28 (1989) 3645-3650. https://doi.org/10.1021/bi00435a004.

[45] L. Nathanson, Z. Gromet-Elhanan, Mutations in the $\beta$-subunit Thr159 and Glu184 of the Rhodospirillum rubrum FOF1 ATP synthase reveal differences in ligands for the coupled Mg2+- and decoupled Ca2+dependent FOF1 activities, Journal of Biological Chemistry. 275 (2000) 901-905. https://doi.org/10.1074/jbc.275.2.901.

[46] U. Pick, M. Weiss, A light-dependent dicyclohexylcarbodiimide-sensitive Ca-ATPase activity in chloroplasts which is not coupled to proton translocation, Eur. J. Biochem. 173 (1988) 623-628.

[47] V. De Col, E. Petrussa, V. Casolo, E. Braidot, G. Lippe, A. Filippi, C. Peresson, S. Patui, A. Bertolini, V. Giorgio, V. Checchetto, A. Vianello, P. Bernardi, M. Zancani, Properties of the Permeability Transition of Pea Stem Mitochondria, Front Physiol. 9 (2018) 1626. https://doi.org/10.3389/fphys.2018.01626.

[48] D.S. Perlin, L.R. Latchney, J.G. Wise, A.E. Senior, Specificity of the proton adenosinetriphosphatase of Escherichia coli for adenine, guanine, and inosine nucleotides in catalysis and binding, Biochemistry. 23 (1984) 4998-5003.

[49] D.G. Nicholls, S.J. Ferguson, 7 - ATP Synthases and Bacterial Flagella Rotary Motors, in: Bioenergetics (Fourth Edition), Academic Press, Boston, 2013: pp. 197-220. https://doi.org/10.1016/B978-0-12388425-1.00007-5.

[50] P.D. Boyer, Catalytic site occupancy during ATP synthase catalysis, FEBS Lett. 512 (2002) 29-32. https://doi.org/10.1016/S0014-5793(02)02293-7.

[51] Y.M. Milgrom, R.L. Cross, Rapid hydrolysis of ATP by mitochondrial F1-ATPase correlates with the filling of the second of three catalytic sites, Proc. Natl. Acad. Sci. U.S.A. 102 (2005) 13831-13836. https://doi.org/10.1073/pnas.0507139102.

[52] L. Li, P. Rose, P.K. Moore, Hydrogen sulfide and cell signaling, Annu. Rev. Pharmacol. Toxicol. 51 (2011) 169-187. https://doi.org/10.1146/annurev-pharmtox-010510-100505.

[53] L. Li, P.K. Moore, Putative biological roles of hydrogen sulfide in health and disease: a breath of not so fresh air?, Trends Pharmacol. Sci. 29 (2008) 84-90. https://doi.org/10.1016/j.tips.2007.11.003.

[54] A.K. Mustafa, M.M. Gadalla, N. Sen, S. Kim, W. Mu, S.K. Gazi, R.K. Barrow, G. Yang, R. Wang, S.H. Snyder, HS signals through protein S-Sulfhydration, Science Signaling. 2 (2009). https://doi.org/10.1126/scisignal.2000464.

[55] H. Itoh, A. Takahashi, K. Adachi, H. Noji, R. Yasuda, M. Yoshida, K. Kinosita, Mechanically driven ATP synthesis by F1-ATPase, Nature. 427 (2004) 465-468. https://doi.org/10.1038/nature02212.

[56] K. Módis, Y. Ju, A. Ahmad, A.A. Untereiner, Z. Altaany, L. Wu, C. Szabo, R. Wang, S-Sulfhydration of ATP synthase by hydrogen sulfide stimulates mitochondrial bioenergetics, Pharmacol. Res. 113 (2016) 116124. https://doi.org/10.1016/j.phrs.2016.08.023.

[57] S.-B. Wang, C.I. Murray, H.S. Chung, J.E. Van Eyk, Redox regulation of mitochondrial ATP synthase, Trends Cardiovasc. Med. 23 (2013) 14-18. https://doi.org/10.1016/j.tcm.2012.08.005.

[58] S. Nesci, F. Trombetti, V. Ventrella, A. Pagliarani, Post-translational modifications of the mitochondrial F1FO-ATPase, Biochim. Biophys. Acta. 1861 (2017) 2902-2912. https://doi.org/10.1016/j.bbagen.2017.08.007.

[59] A. Pagliarani, S. Nesci, F. Trombetti, V. Ventrella, Thiol-Related Regulation of the Mitochondrial F1FOATPase Activity, in: S. Chakraborti, N.S. Dhalla (Eds.), Regulation of Ca2+-ATPases,V-ATPases and FATPases, Springer International Publishing, 2016: pp. 441-458. https://doi.org/10.1007/978-3-31924780-9_21.

[60] A.S. Papu John, S. Kundu, S. Pushpakumar, M. Amin, S.C. Tyagi, U. Sen, Hydrogen sulfide inhibits Ca2+induced mitochondrial permeability transition pore opening in type-1 diabetes, Am. J. Physiol. Endocrinol. Metab. 317 (2019) E269-E283. https://doi.org/10.1152/ajpendo.00251.2018. 
[61] É.G.A. Miranda, J.C. Araujo-Chaves, C. Kawai, A.M.M. Brito, I.W.R. Dias, J.T. Arantes, I.L. NantesCardoso, Cardiolipin Structure and Oxidation Are Affected by Ca2+ at the Interface of Lipid Bilayers, Front. Chem. 7 (2020). https://doi.org/10.3389/fchem.2019.00930.

[62] R. Fiorini, A. Pagliarani, S. Nesci, M. Pirini, E. Tucci, V. Ventrella, Structural and functional changes in gill mitochondrial membranes from the Mediterranean mussel Mytilus galloprovincialis exposed to tri-nbutyltin, Environ. Toxicol. Chem. 31 (2012) 877-884. https://doi.org/10.1002/etc.1764.

[63] K.N. Alavian, G. Beutner, E. Lazrove, S. Sacchetti, H.-A. Park, P. Licznerski, H. Li, P. Nabili, K. Hockensmith, M. Graham, G.A. Porter, E.A. Jonas, An uncoupling channel within the c-subunit ring of the F1FO ATP synthase is the mitochondrial permeability transition pore, Proc. Natl. Acad. Sci. U.S.A. 111 (2014) 10580-10585. https://doi.org/10.1073/pnas.1401591111.

[64] V. Giorgio, S. von Stockum, M. Antoniel, A. Fabbro, F. Fogolari, M. Forte, G.D. Glick, V. Petronilli, M. Zoratti, I. Szabó, G. Lippe, P. Bernardi, Dimers of mitochondrial ATP synthase form the permeability transition pore, Proc. Natl. Acad. Sci. U.S.A. 110 (2013) 5887-5892. https://doi.org/10.1073/pnas.1217823110.

[65] M. Bonora, A. Bononi, E. De Marchi, C. Giorgi, M. Lebiedzinska, S. Marchi, S. Patergnani, A. Rimessi, J.M. Suski, A. Wojtala, M.R. Wieckowski, G. Kroemer, L. Galluzzi, P. Pinton, Role of the c subunit of the FO ATP synthase in mitochondrial permeability transition, Cell Cycle. 12 (2013) 674-683. https://doi.org/10.4161/cc.23599.

[66] J. Karch, M.J. Bround, H. Khalil, M.A. Sargent, N. Latchman, N. Terada, P.M. Peixoto, J.D. Molkentin, Inhibition of mitochondrial permeability transition by deletion of the ANT family and CypD, Sci Adv. 5 (2019) eaaw4597. https://doi.org/10.1126/sciadv.aaw4597.

\section{Figure captions}

Figure 1. Mitochondrial ATPase activity sustained by $\mathrm{Ca}^{2+}$ or by $\mathrm{Mg}^{2+}$. The oligomycin-sensitive ATPase activity ( ) and the oligomycin-insensitive ATPase activity ( ) are expressed as percentages of the total mitochondrial ATPase activity sustained by $\mathrm{Ca}^{2+}$ or $\mathrm{Mg}^{2+}$, respectively. Data expressed as column chart represent the mean $\pm \mathrm{SD}$ (vertical bars) from three experiments carried out on different mitochondrial preparations. * indicates significantly different values $(P \leq 0.05)$.

Figure 2. Plots to obtain the kinetic parameters of the mitochondrial $\mathrm{Mg}^{2+}$ - and $\mathrm{Ca}^{2+}$-dependent $\mathrm{F}_{1} \mathrm{~F}_{\mathrm{O}}-$ ATPases. A and B) Hill plots of the $\mathrm{Mg}^{2+}$-ATPase $(\bullet)$ and the $\mathrm{Ca}^{2+}$-ATPase $(\circ)$. C and D) Lineweaver-Burk plots of the $\mathrm{Mg}^{2+}$-ATPase $(\bullet)$ and $\mathrm{Ca}^{2+}$-ATPase $(\circ)$. Data represent the mean $\pm \mathrm{SD}$ from three independent experiments carried out on distinct mitochondrial preparations.

Figure 3. In vitro response of the mitochondrial $\mathrm{Mg}^{2+}$ - and $\mathrm{Ca}^{2+}$-dependent $\mathrm{F}_{1} \mathrm{~F}_{\mathrm{O}}$-ATPase activities to NaHS. The $\mathrm{F}_{1} \mathrm{~F}_{\mathrm{O}}$-ATPase activities of the mitochondrial $\mathrm{Mg}^{2+}$-ATPase $(\bullet)$ and $\mathrm{Ca}^{2+}$-ATPase $(0)$ are plotted against NaHS concentrations (logarithmic scale). Each point represents the mean \pm SD from three experiments on distinct mitochondrial preparations. 
Figure 4. Evaluation of mPTP opening. Representative curves of the calcium retention capacity (CRC) in mitochondrial preparations. CRC was monitored in response to subsequent $10 \mu \mathrm{MCaCl}_{2}$ pulses (shown by the arrows), as detailed in the Materials and Methods section, in the absence (control) and presence of 50 or $100 \mu \mathrm{M}$ NaHS, and in the presence of the mPTP inhibitors $2 \mathrm{mM}$ MgADP or $1 \mu \mathrm{M}$ Ruthenium Red (RR). The experiments were carried out in triplicate on three distinct mitochondrial preparations. 


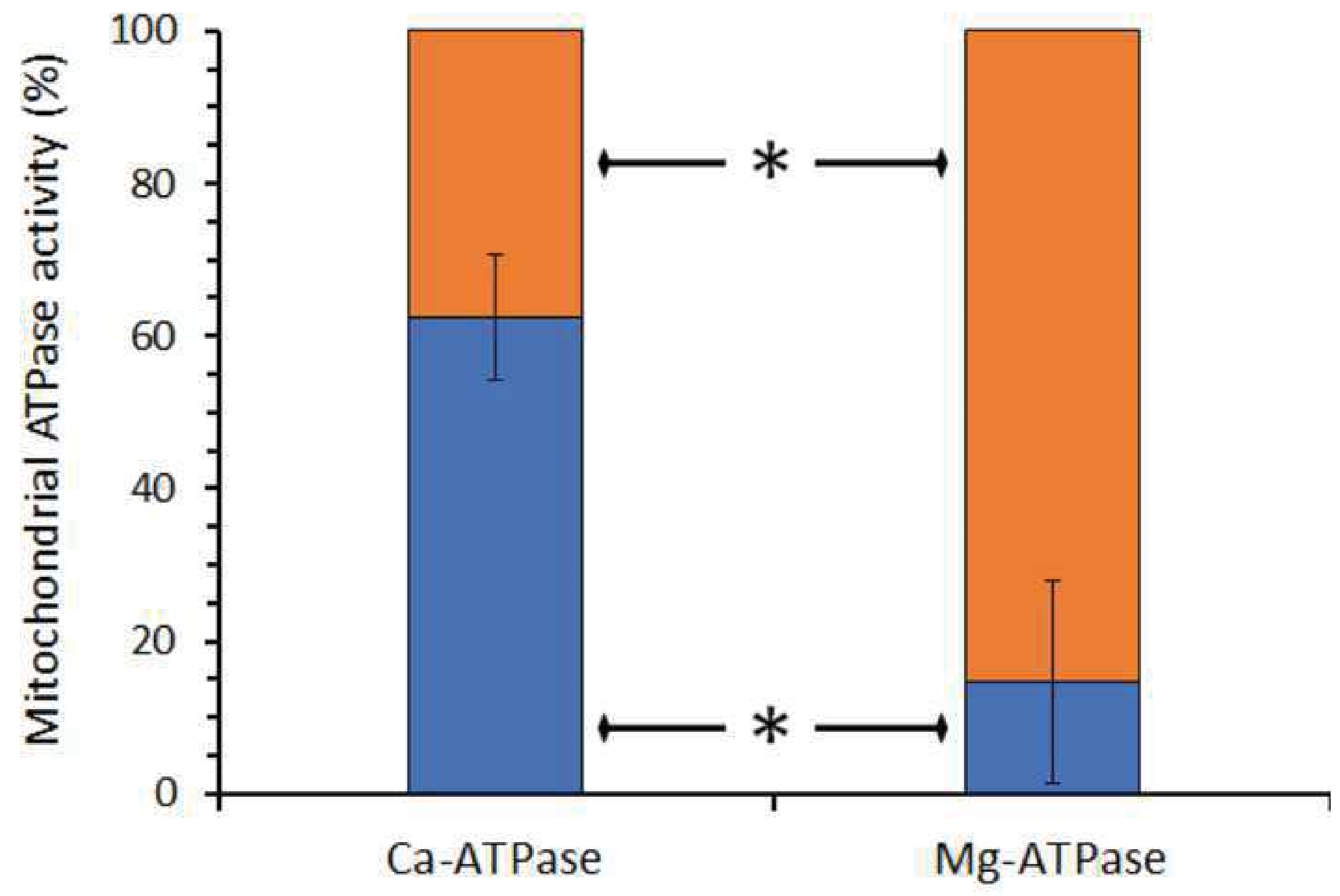



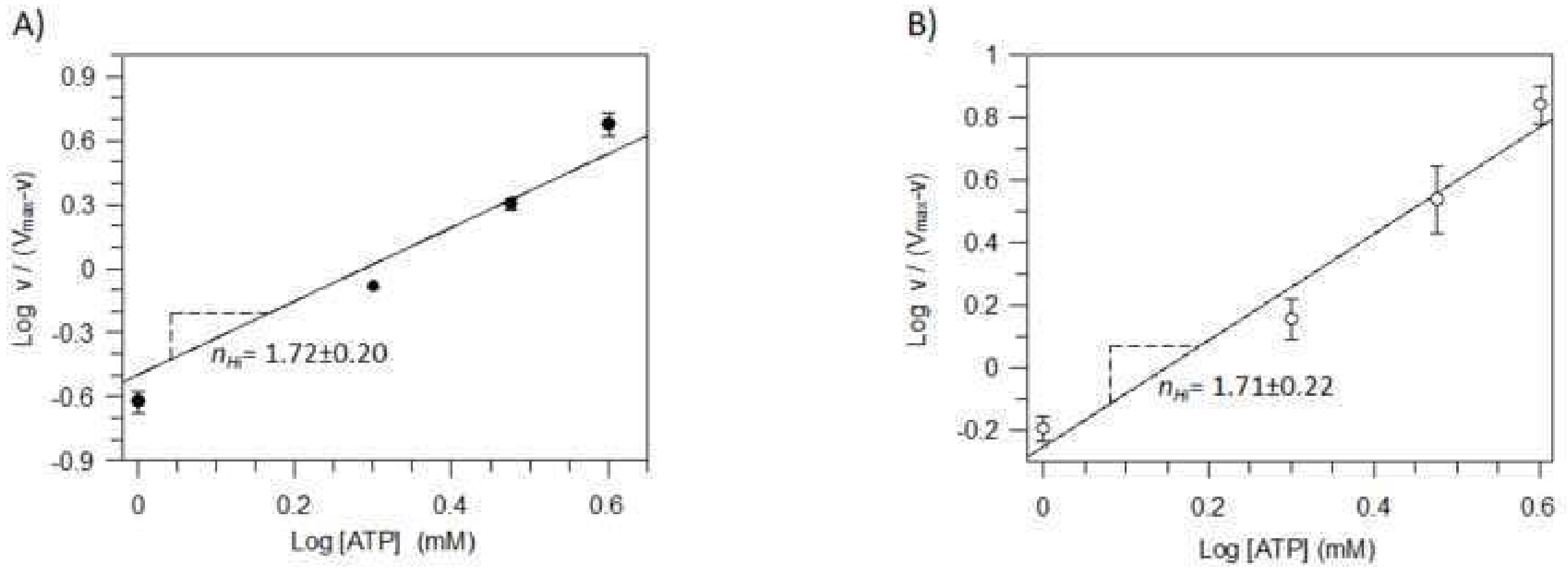

C)

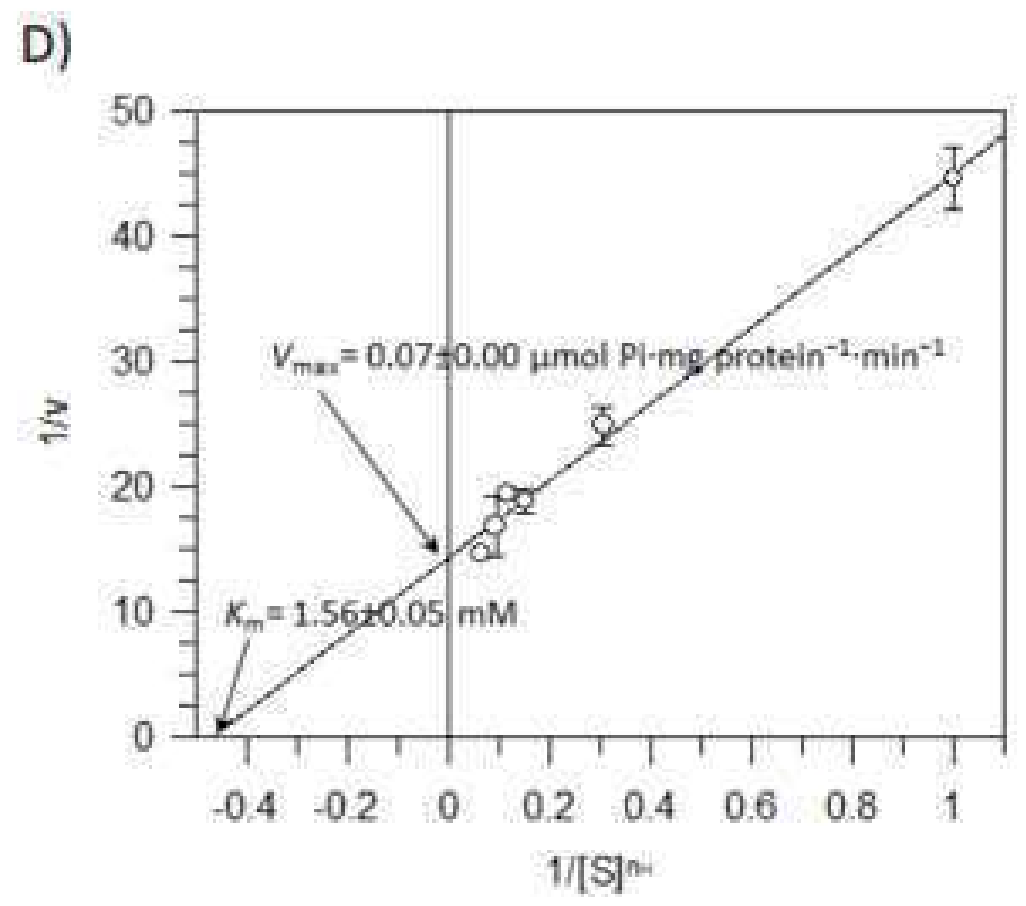




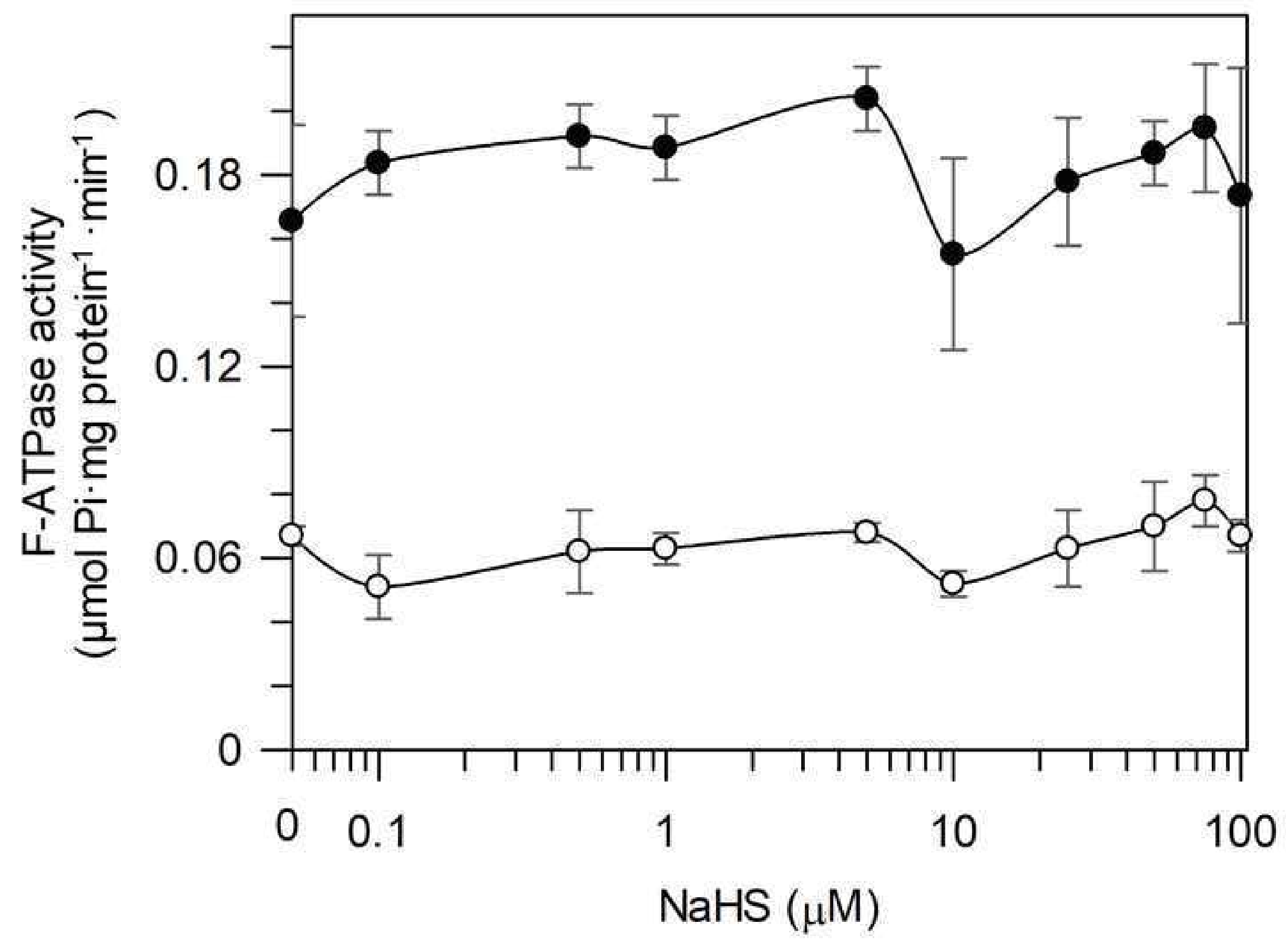




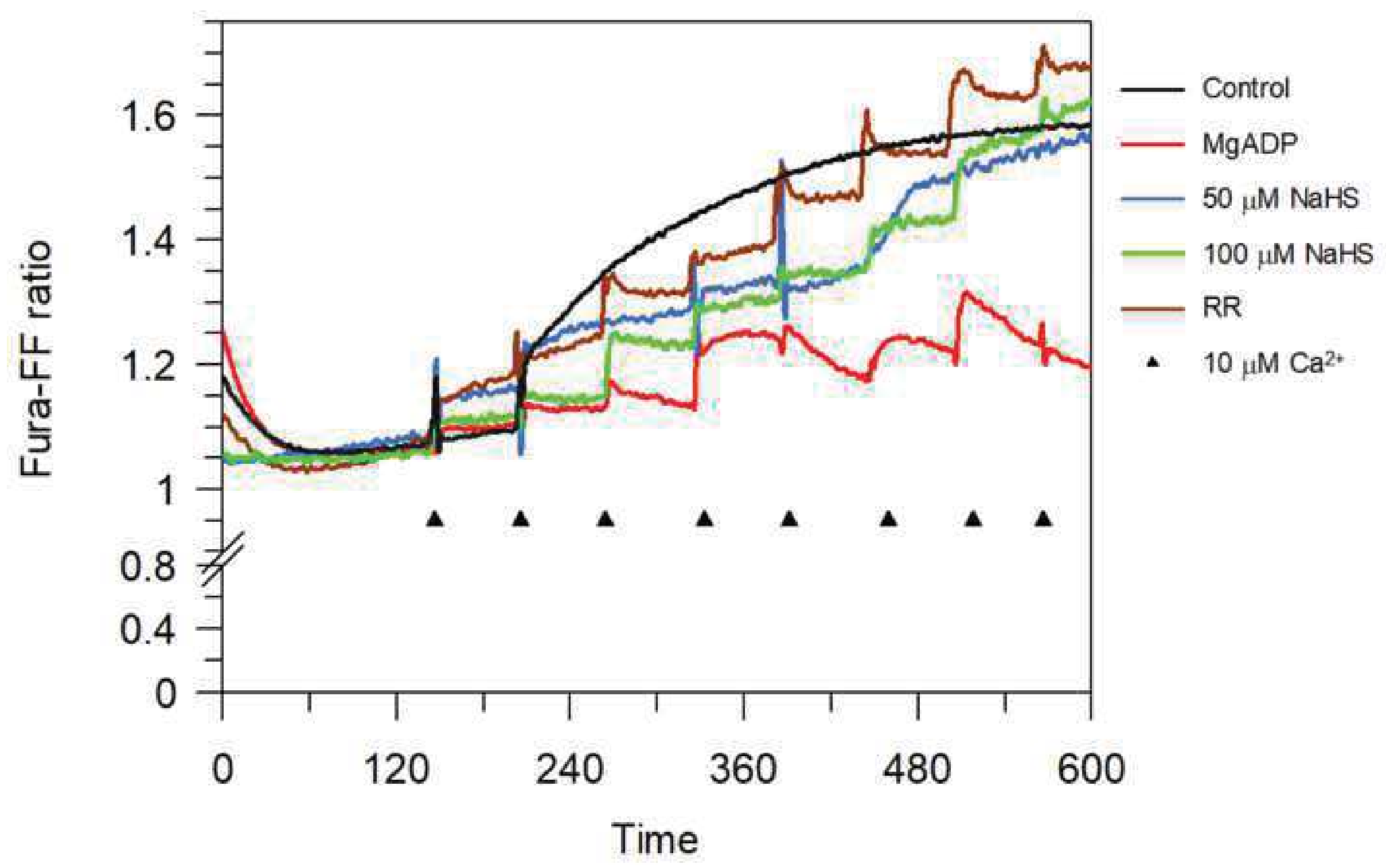

